\title{
Environmentally friendly system for the degradation of multipesticide residues in aqueous media by the Fenton's reaction
}

\author{
Bruno de S. Guimarães • Natiele Kleemann • Sergiane S. Caldas • \\ Fabiane P. Costa • Maria A. K. Silveira • Fabio A. Duarte • \\ Ednei G. Primel
}

Received: 8 April 2013 / Accepted: 11 June 2013 / Published online: 30 June 2013

(C) Springer-Verlag Berlin Heidelberg 2013

\begin{abstract}
A Fenton oxidation system employing zero-valent iron (whose source was swarf, a residue of metallurgical industries, in powder form) and hydrogen peroxide for the treatment of an aqueous solution with six pesticides was developed, and the effect of the iron metal content, $\mathrm{pH}$, and hydrogen peroxide concentration was evaluated. The characterization of the aqueous solution resulted in: $\mathrm{pH} 5.6,105 \mathrm{mg} \mathrm{L}^{-1}$ of dissolved organic carbon, and 44.6 NTU turbidity. In addition, the characterization of the swarf by FAAS and ICP-MS showed $98.43 \pm 7.40 \%$ of zero-valent iron. The removal was strongly affected by the content of iron metal, $\mathrm{pH}$, and hydrogen peroxide concentration. The best degradation conditions were $2.0 \mathrm{~g}$

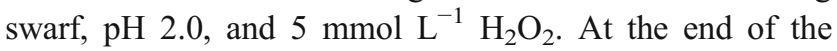
treatment, the pesticide degradation ranged from 60 to $100 \%$, leading to $55 \%$ mineralization. Besides, all hydrogen peroxide was consumed and the determination of total dissolved iron resulted in $2 \mathrm{mg} \mathrm{L}^{-1}$. Thus, the advantages of this system are rapid degradation (up to $20 \mathrm{~min}$ ), high-degradation rates, simple handling, and low cost.
\end{abstract}

Responsible editor: Philippe Garrigues

Electronic supplementary material The online version of this article (doi:10.1007/s11356-013-1932-2) contains supplementary material, which is available to authorized users.

B. de S. Guimarães $\cdot$ N. Kleemann $\cdot$ S. S. Caldas · F. P. Costa $\cdot$ M. A. K. Silveira $\cdot$ F. A. Duarte $\cdot$ E. G. Primel $(\bowtie)$

Post-graduation Program in Technological and Environmental Chemistry, Escola de Química e Alimentos, Laboratório de Análise de Compostos Orgânicos e Metais (LACOM), Universidade Federal do Rio Grande, Av Itália, km 8, s/n, Rio Grande 96201-900,

Rio Grande do Sul, Brazil

e-mail: eprimelfurg@gmail.com
Keywords Environmentally friendly system • Multipesticide degradation · Zero-valent iron . Fenton's reaction

\section{Introduction}

There has been a growing concern about the quality of water resources in the last decades. Economic growth, together with worldwide technological and agricultural development, has brought about environmental pollution (Oturan et al. 2011). In this context, pesticides represent a risk factor for the quality of water resources because these substances are generally toxic and non-biodegradable (Cabrera et al. 2010).

Some studies have recently reported the risk of water contamination by pesticides in the south of Brazil, as well as the detection of pesticides in groundwater, surface water, and drinking water (Cabrera et al. 2008; Caldas et al. 2010; Demoliner et al. 2010). Likewise, many researchers have shown the contamination of water resources all over the world (Fatta et al. 2006; 2007). Therefore, one of the most serious challenges, nowadays, is the protection of water resources by eliminating a significant part of the pollution caused by toxic and hazardous organic contaminants (Melo et al. 2009; Oturan et al. 2011). Classical biological oxidation has failed to eliminate toxic compounds or recalcitrant organic contaminants (Martín et al. 2010; Pérez et al. 2006). Moreover, physicochemical processes, such as adsorption on activated carbon, flocculation, and membrane filtration, only transfer the compounds from one phase to another without destroying them (Hermosilla et al. 2009; Martín et al. 2010; Oturan et al. 2011; Oller et al. 2011). Besides, the product that results from these processes must be considered a residue because it requires a supplementary technique to eliminate the total compound content (Arruda and Jardim 2007; Oturan et al. 
2011). Therefore, efficient oxidation technologies must be developed. Advanced oxidation processes (AOPs) can be considered promising alternative methods in the case of several pollutants and viable alternatives to conventional technologies (Hermosilla et al. 2009; Kallel et al. 2010; Masomboon et al. 2010; Gözmen et al. 2009; Zapata et al. 2009). Many researches on pesticide degradation by AOPs have recently been published (Arruda and Jardim 2007; Barreiro et al. 2007; Cabrera et al. 2010; Fan et al., 2011b; Kassinos et al. 2008; 2009; Pérez et al. 2006; Oturan et al. 2011).

AOPs are oxidation technologies based on the generation of hydroxyl radical which is a powerful $(2.8 \mathrm{~V}$ redox standard potential vs. hydrogen electrode) unselect oxidant. AOPs are able to oxidize and mineralize a wide variety of organic compounds either by generating water, carbon dioxide, and inorganic ions (Klavarioti et al. 2011). Due to the high reactivity of hydroxyl radicals, the attack is non-selective and enables the treatment of wastewater containing different organic pollutants. The Fenton's process stands out among the AOPs because it is easy to handle and very efficient. Due to these characteristics, it has been used in several studies (Arruda and Jardim 2007; Barreiro et al. 2007; Hermosilla et al. 2009; Khan et al. 2009; Jiang et al. 2010; Martín et al. 2010; Fan et al. 2011a, b; Oller et al. 2011; Oturan et al. 2011).

The Fenton's reaction is based on the decomposition of hydrogen peroxide by $\mathrm{Fe}^{2+}$ to generate hydroxyl radicals, as described in Eq. (1) (Walling 1975).

$$
\mathrm{Fe}^{2+}+\mathrm{H}_{2} \mathrm{O}_{2} \rightarrow \mathrm{Fe}^{3+}+\mathrm{HO}^{\cdot}+\mathrm{OH}^{-}
$$

For an efficient reaction, a stoichiometric amount of ferrous ions and hydrogen peroxide is required. Benatti et al. have reported in their research work that the oxidative degradation of organic contaminants can be successfully accomplished by the Fenton's reaction. However, the concentration of certain inorganic constituents, such as sulfate, still remained extremely high for effluent discharge (Benatti et al. 2006, 2009). It usually means that huge quantities of these constituents need to be disposed of after the reaction is complete. However, when zero-valent iron is used in place of ferrous salts, the following reactions can occur

$$
\begin{aligned}
& \mathrm{Fe}^{0}+2 \mathrm{H}^{+} \rightarrow \mathrm{Fe}^{2+}+\mathrm{H}_{2} \\
& \mathrm{Fe}^{0}+\mathrm{O}_{2}+2 \mathrm{H}^{+} \rightleftharpoons \mathrm{Fe}^{2+}+\mathrm{H}_{2} \mathrm{O}_{2} \\
& \mathrm{Fe}^{0}+\mathrm{H}_{2} \mathrm{O}_{2} \rightleftharpoons \mathrm{Fe}^{2+}+\mathrm{HO} \\
& 2 \mathrm{Fe}^{3+}+\mathrm{Fe}^{0} \rightarrow 3 \mathrm{Fe}^{2+}
\end{aligned}
$$

In an acid medium with no oxygen, the surface of the metal iron corrodes, thus giving rise to ferrous ions and hydrogen gas (Eq. (2)). The ferrous ions generated in Eq. (2) in the presence of hydrogen peroxide react quickly via the conventional Fenton's reaction (Eq. (1)), producing hydroxyl radical and ferric ions (Namkung et al. 2008; Kallel et al. 2009). On the other hand, the metal iron can also decompose hydrogen peroxide in the presence of oxygen. In this case, dissolved oxygen is the main electron acceptor, resulting in rapid corrosion (Eq. (3)). Concurrently, the metal iron could cause the reduction of hydrogen peroxide to yield hydroxyl radical, as described in Eq. (4), and the ferrous ion can promote the subsequent decomposition of hydrogen peroxide as shown in Eq. (1) (Scherer et al. 2001; Gooddy et al. 2002; Satapanajaru et al. 2003).

The ferric ions can be reduced to ferrous ions by the metal iron surface according to Eq. (5) (Namkung et al. 2008; Kallel et al. 2009). This is the main advantage of the Fenton's system employing zero-valent iron.

However, small amounts of ferric species are formed, which is an inevitable fact. Nevertheless, this fact does not make the process unviable because this undesirable product will be able to start a new Fenton's reaction (Oturan et al. 2008; Jiang et al. 2010).

Therefore, this study aimed to develop and optimize an environmentally friendly and sustainable Fenton oxidation system employing zero-valent iron (a residue of the metallurgical industry) and hydrogen peroxide for the degradation of an aqueous solution with six different classes of pesticides and chemical groups, besides evaluating the effect of the following parameters: the amount of metal iron, $\mathrm{pH}$, and the hydrogen peroxide concentration.

\section{Materials and methods}

\section{Instrumentation}

For the swarf characterization, the metal iron $\left(\mathrm{Fe}^{0}\right)$ measurements were carried out by a Model Vario 6 FL Flame Atomic Absorption Spectrometer (Analytik Jena AG, Germany), equipped with a deuterium background corrector and a hollow-cathode lamp for iron, operating at $8 \mathrm{~mA}$ (wavelength: $248.3 \mathrm{~nm}$; spectral bandwidth: $0.2 \mathrm{~nm}$ ). A conventional air/acetylene burner (10-cm slit) was used. Integrated absorbance with a 1-s integration time was used for signal evaluation.

An Inductively Coupled Plasma Mass Spectrometer (PerkinElmer SCIEX, Model Elan DRC II, Thornhill, Canada), equipped with a concentric nebulizer (Meinhard Associates, Golden, USA), a cyclonic spray chamber (Glass Expansion, Inc., West Melbourne, Australia), and a quartz torch with a quartz injector tube (2-mm i.d.) was used for $\mathrm{Cr}$, $\mathrm{Cu}, \mathrm{Ni}, \mathrm{Pb}, \mathrm{Sn}$, and $\mathrm{Sr}$ determination. The nebulizer gas flow rate, the ion lens voltage, and the torch alignment were adjusted according to the manufacturer's instructions by using conventional nebulization. Monitored ions were ${ }^{52} \mathrm{Cr}$, ${ }^{63} \mathrm{Cu},{ }^{60} \mathrm{Ni},{ }^{208} \mathrm{~Pb},{ }^{120} \mathrm{Sn}$, and ${ }^{88} \mathrm{Sr}$. The plasma power and the 
nebulizer gas flow rate were $1,300 \mathrm{~W}$ and $1.10 \mathrm{~L} \mathrm{~min}^{-1}$, respectively.

During the optimization of the zero-valent iron system, high-performance liquid chromatography with diode array detector (HPLC-DAD) was employed. LC-DAD separation was performed by using an HPLC apparatus consisting of a column Thermo BDS Hypersil C18 particle size $5 \mu \mathrm{m}(250 \times 4.6 \mathrm{~mm}$ i.d.), from Thermo Scientific, a Waters 600 pump model, associated with a Waters 2996 Photodiode Array Detector and a Rheodyne $20-\mu \mathrm{L}$ loop injector, connected to an Empower PDA software for data acquisition. The UV spectra were recorded in the $210-400 \mathrm{~nm}$ range.

For the determination by LC-DAD, the mobile phase composition was methanol (A) and ultrapure water $\mathrm{pH} 4.0$ (B) acidified with phosphoric acid 1:1 $(v / v)$. The gradient elution mode was: 0-6 min, $40 \% \mathrm{~A}$; 6-7 min, 40-75\% A; 7-25 min, $75 \% \mathrm{~A} ; 25-26 \mathrm{~min}, 75-40 \% \mathrm{~A}$; and $26-30 \mathrm{~min}$, $40 \% \mathrm{~A}$. The flow rate was: $0-6 \mathrm{~min}, 0.8 \mathrm{~mL} \mathrm{~min}^{-1} ; 6-7 \mathrm{~min}$, $0.8-1.2 \mathrm{~mL} \mathrm{~min}^{-1} ; 7-25 \mathrm{~min} 1.2 \mathrm{~mL} \mathrm{~min}^{-1} ; 25-26 \mathrm{~min}, 1.2-$ $0.8 \mathrm{~mL} \mathrm{~min}^{-1}$; and $26-30 \mathrm{~min}, 0.8 \mathrm{~mL} \mathrm{~min}^{-1}$, totalling to a 30 -min running time. The mobile phases were degassed for $30 \mathrm{~min}$ in an ultrasonic bath before use.

The liquid chromatography coupled to electrospray ionization tandem mass spectrometry (LC-ESI-MS/MS) was used to confirm the pesticide degradation and evaluate the formation of carbofuran-3-hidroxy and 3,4 DCA, byproducts of pesticides carbofuran and diuron, respectively. The LC-ESI-MS/MS was performed by a Waters Alliance 2695 Separations Module. The mass spectrometry was carried out by a Micromass Quattro Micro API with an ESI interface, connected to a Masslynx version 4.1, 2005 software for data acquisition. The liquid chromatography was performed by an XTerra analytical column $3.5 \mu \mathrm{m}$ $(50 \times 3 \mathrm{~mm}$, i.d.) (Waters, Milford, MA, USA). The determinations by LC-ESI-MS/MS were performed as previously described by Demoliner et al. (2010). The figure of merits of chromatography methodology can be seen at Table 1 in supplementary data.

The ion chromatography (IC) with conductivity detector was used to confirm the mineralization of pesticides. Therefore, the determination of $\mathrm{NH}_{4}{ }^{+}, \mathrm{NO}_{2}{ }^{-}, \mathrm{NO}_{3}{ }^{-}$, $\mathrm{Cl}^{-}, \mathrm{PO}_{4}{ }^{2-}$, and $\mathrm{SO}_{4}{ }^{2-}$ was carried out by an IC compact Pro $881 \mathrm{Metrohm}$ equipped with autosampler, quaternary pump, column oven, chemical suppression system, and digital conductivity detector iDetector connected to MagIC NetTM software for data acquisition (Metrohm, Herisau, Suíça). The determination of ions was carried out by the method employed and established by Metrohm (ANC-135 and ANS-257, 2012).

The determination of the total dissolved iron $\left(\mathrm{Fe}^{2+}\right)$ which remained at the end of the process was measured by a UVvis Spectrophotometer (model UV 2550, Shimadzu, Japan) connected to UV-Probe software for data acquisition, according to norm NBR 13934, issued by the Associação
Brasileira de Normas Técnicas (Associação Brasileira de Normas Técnicas ABNT 2010). This determination was based on the reaction between ortho-phenanthroline and $\mathrm{Fe}^{2+}$, thus, giving rise to orange complexes at $\mathrm{pH}<5$.0. Ferric ions can be reduced to ferrous ions by the addition of ascorbic acid.

The hydrogen peroxide residual content was measured by a UV-vis Spectrophotometer (model UV 2550, Shimadzu, Japan) connected to UV-Probe software for data acquisition, according to the colorimetric method developed by Eisenberg (Eisenberg 1975). This method was based on the reaction between hydrogen peroxide and titanium sulfate, which generates a yellow complex.

The Total Organic Carbon (TOC) content was measured by a TOC Analyzer (TOC, model TOC-V CPH, Shimadzu, Japan) and a non-purgeable organic carbon (NPOC) analysis was carried out. Turbidity was measured by a $2100 \mathrm{P}$ Turbidimeter Hach (Hach Company, USA).

\section{Materials and chemicals}

Hydrogen peroxide $(29 \%, w / w)$ and phosphoric acid ( $85 \%$, $w / w)$ analytical grade were purchased from Synth (Brazil) and from Tedia (USA), respectively.

The aqueous solution used during the degradation experiments was prepared in the laboratory by adding $10 \mathrm{mg}$ of each pesticide (Fig. 1) to 1-L distilled water. Some of the pesticides selected in this study had been detected in a previous research. In groundwater samples, carbofuran, clomazone, and tebuconazole were detected in concentrations ranging from $0.20 \mu \mathrm{g} \mathrm{L}^{-1}$ to $10.40 \mu \mathrm{g} \mathrm{L}^{-1}$ (Caldas et al. 2010). In drinking water and surface water, diuron and tebuconazole were detected in concentrations of $0.5 \mu \mathrm{g} \mathrm{L}{ }^{-1}$ (Demoliner et al. 2010).

\section{Experimental procedure}

The system was based on the spontaneous corrosion of metal iron on the swarf surface in the presence of hydrogen peroxide and in acidic conditions. It produces ferrous ions, which react with hydrogen peroxide in the Fenton's reaction, resulting in hydroxyl radicals (Kallel et al. 2009). All experiments were carried out in a special system designed for the degradation of an aqueous solution, as shown in Fig. 2. The system consists of a 1-L separation funnel, a 1-L beaker, and a PVC gutter (1-m long) whose magnetic boards hold the swarf. One liter of aqueous solution (containing $10 \mathrm{mg} \mathrm{L}^{-1}$ of each pesticide), previously acidified with phosphoric acid, was introduced into the separation funnel, followed by the addition of hydrogen peroxide (ranging from 1 to $10 \mathrm{mmol} \mathrm{L}^{-1}$ ). The solution percolated the gutter for $20 \mathrm{~min}$ at room temperature $\left(25^{\circ} \mathrm{C}\right)$ with neither natural nor artificial light. For sample characterization and degradation checking under different conditions, aliquots were collected before (with and without $\mathrm{pH}$ adjustment and with 
Fig. 1 Chemical structures of the selected pesticides

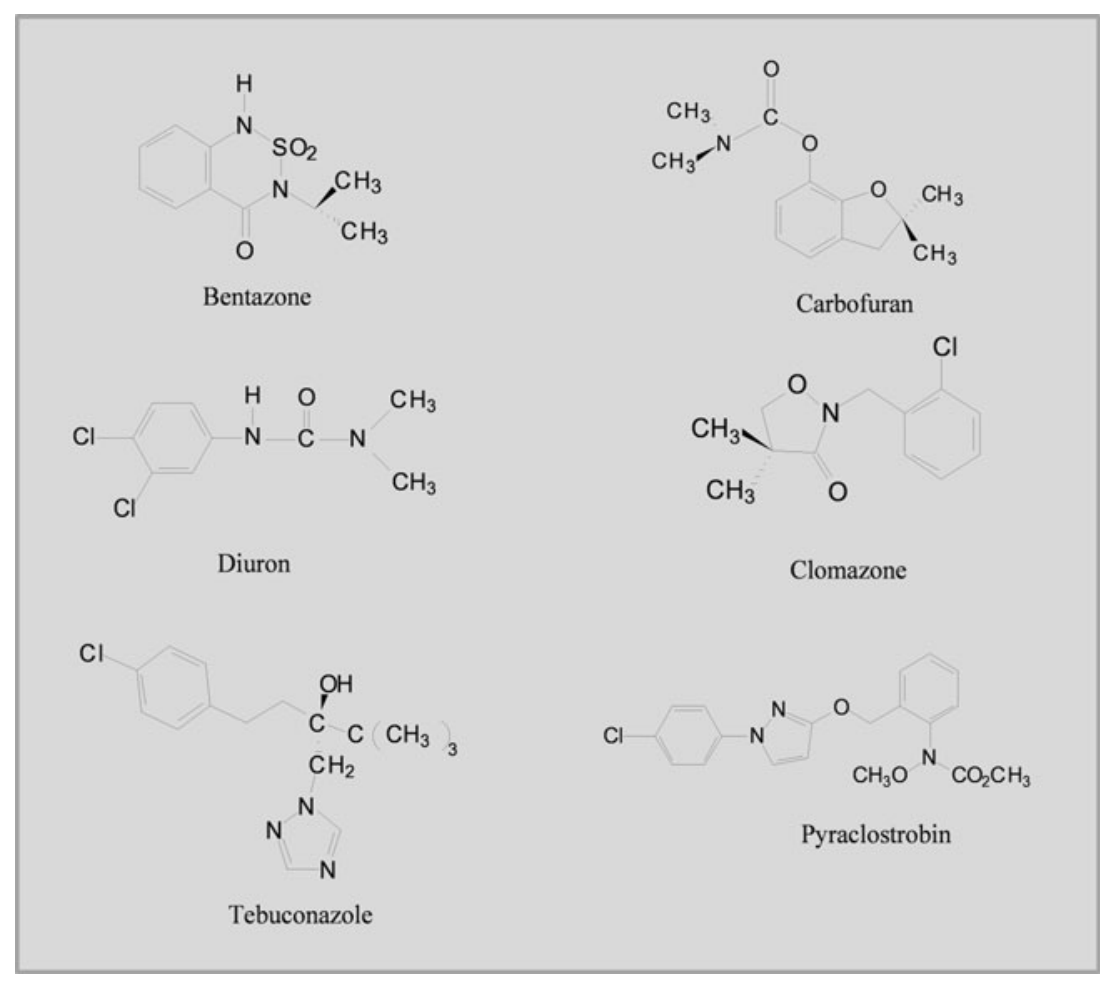

$\mathrm{H}_{2} \mathrm{O}_{2}$ addition) and during the experiment. All aqueous samples were withdrawn and filtered by a PTFE $0.45-\mu \mathrm{m}$, Millipore, Millex ${ }^{\circledR}$ before the analysis by HPLC-DAD, LC-MS/MS, and IC. Samples were mixed with methanol, and stored and cooled at $-18^{\circ} \mathrm{C}$ in order to stop the Fenton's reaction. However, for the TOC content analysis, samples were mixed with $\mathrm{Na}_{2} \mathrm{~S}_{2} \mathrm{O}_{3}$. If methanol had been used in the TOC content analysis, this content would have been affected. On the other hand, the use of $\mathrm{Na}_{2} \mathrm{~S}_{2} \mathrm{O}_{3}$ should be avoided in the chromatographic analysis, mainly for LC-MS/MS, because it may precipitate during the analysis and clog up the chromatograph.

For the swarf characterization by flame atomic absorption spectrometry (FAAS) and inductively coupled plasma mass spectrometry (ICP-MS), about 1-g swarf was digested with $5-\mathrm{mL}$ concentrated $\mathrm{HCl}$ and stirred for $5 \mathrm{~min}$ in a vortex. Afterwards, it was kept at $140{ }^{\circ} \mathrm{C}$ for $2 \mathrm{~h}$ in a hot plate.

\section{Statistical calculations}

All statistical calculations were performed by GraphPad Instat (GraphPad Instat Software Inc, Version 3.00, 1997) software. A $95 \%$ significance level was adopted for all comparisons.

\section{Results and discussion}

Characterization of swarf and aqueous solution

The characterization of the aqueous solution resulted in $\mathrm{pH}$ 5.6, TOC $105 \mathrm{mg} \mathrm{L}^{-1}$ carbon, and 44.6 NTU turbidity. In addition, the characterization of the swarf by FAAS and ICP-MS revealed $98.43 \pm 7.40 \%$ of zero-valent iron, whereas $\mathrm{Cr}, \mathrm{Cu}, \mathrm{Ni}$, $\mathrm{Pb}, \mathrm{Sn}$, and $\mathrm{Sr}$ were detected in the following concentrations: $0.45 \pm 0.02 \mathrm{mg} \mathrm{g}^{-1} ; 0.57 \pm 0.05 \mathrm{mg} \mathrm{g}^{-1} ; 0.16 \pm 0.01 \mathrm{mg} \mathrm{g}^{-1}$; $0.344 \pm 0.015 \mathrm{mg} \mathrm{g}^{-1} ; 0.0265 \pm 0.0003 \mathrm{mg} \mathrm{g}^{-1}$; and $0.0155 \pm 0.0015 \mathrm{mg} \mathrm{g}^{-1}$, respectively.

Effect of $\mathrm{H}_{2} \mathrm{O}_{2}$ concentration on the pesticide degradation efficiency during oxidation

Equation (6) shows that the Fenton's reaction depends on a stoichiometric amount of hydrogen peroxide (Walling 1975). When excessive hydrogen peroxide is employed, it can react with the hydroxyl radical and inhibit the Fenton's reaction. Likewise, in the presence of large amounts of hydrogen peroxide, the oxidation of organic substrates is inhibited (Tang and Tassos 1997; Gulkaya et al. 2006). It occurs because the hydroxyl radical reacts with the excess of hydrogen peroxide to produce a hydroperoxyl radical, which is less reactive than the hydroxyl one, according to Eq. (6) (Walling 1975).

$$
\mathrm{H}_{2} \mathrm{O}_{2}+\mathrm{HO}^{\cdot} \rightarrow \mathrm{HO}_{2}+\mathrm{H}_{2} \mathrm{O}
$$

In addition, the excess of $\mathrm{H}_{2} \mathrm{O}_{2}$ can also affect the concentration of ferrous ions in the oxidation reaction because ferric ions react with hydrogen peroxide yielding Fe(III)hydroperoxy complexes (Laat and Gallard 1999). Thus, ferric ions cannot be reduced to ferrous ions by the metal iron surface, as suggested by Eq. (5). 


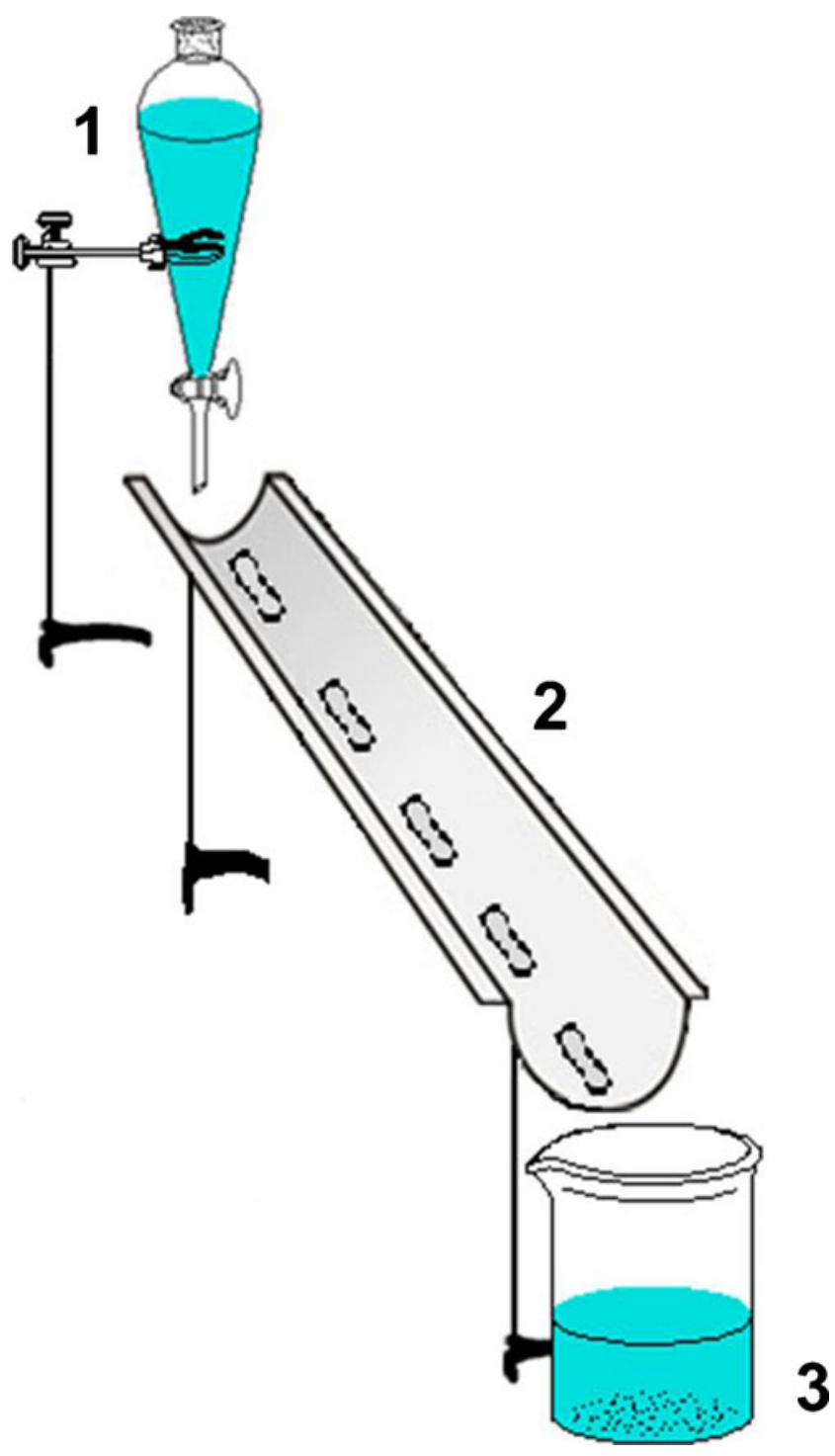

Fig. 2 Illustration of the system designed for the degradation of pesticides (1 1-L separation funnel containing synthetic wastewater previously acidified and with hydrogen peroxide; 2 PVC gutter whose magnetic boards hold the swarf; 31 -L beaker containing wastewater after percolated by PVC gutter)

Therefore, to determine the effect of the hydrogen peroxide concentration on the degradation of the pesticides in the synthetic wastewater, the amount of swarf and the $\mathrm{pH}$ value were fixed, while the hydrogen peroxide concentration ranged from 1 to $10 \mathrm{mmol} \mathrm{L}^{-1}$. Results of these experiments have been reported in Fig. 3. As shown in Fig. 3, degradation rates increase gradually, up to $5 \mathrm{mmol} \mathrm{L}^{-1} \mathrm{H}_{2} \mathrm{O}_{2}$. Hydrogen peroxide concentration above $5 \mathrm{mmol} \mathrm{L}^{-1}$ reduces the degradation rates of all pesticides.

Finally, a $t$ test was carried out to compare the results obtained for degradation in ten experiments. The Tukey's multiple comparison test was used to indicate significant differences among the main degradation with $95 \%$ significance level adopted for all comparisons. No significant

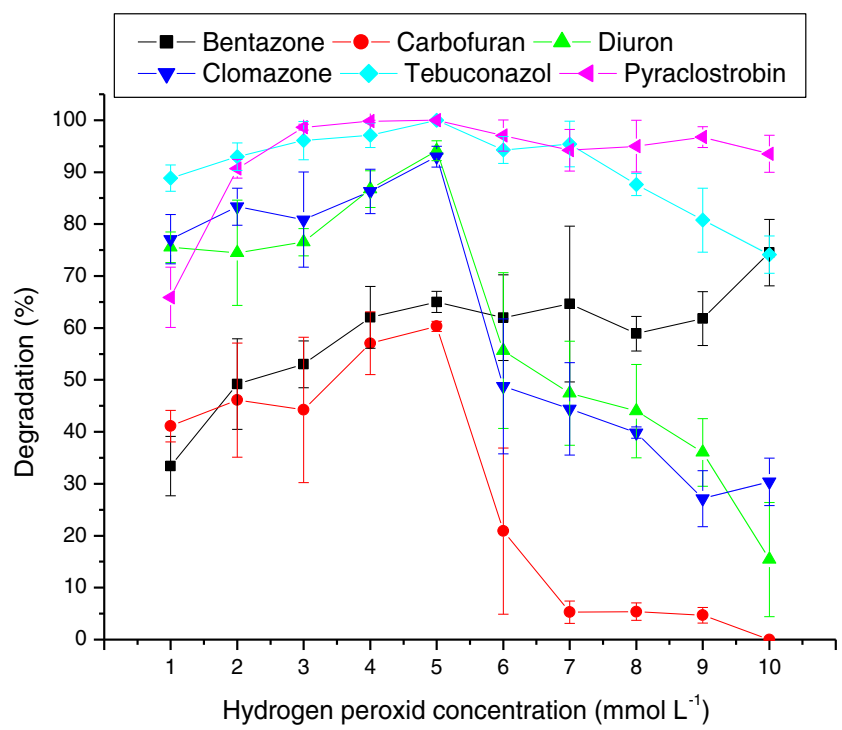

Fig. 3 Effect of different $\mathrm{H}_{2} \mathrm{O}_{2}$ concentrations on the pesticide degradation by Fenton's oxidation, obtained after 20 min (experimental conditions: $\mathrm{pH} 2.0 ; 2.0$-g iron metal). Bars indicate the RSD percentage values

difference ( $t$ test, $P>0.05$ ) was found from 2 to $5 \mathrm{mmol} \mathrm{L}^{-1}$. However, it is important to mention that when $5 \mathrm{mmol} \mathrm{L}^{-1}$ hydrogen peroxide was used, the standard deviation was lower. Thus, this concentration was used for further experiments.

\section{Effect of $\mathrm{pH}$}

In the absence of a substrate, the hydroxyl radical generated in Eq. (1) can oxidize the second ferrous ion. It shows that the Fenton's reaction is extremely dependent on the $\mathrm{pH}$. In this sense, only in acid conditions, the hydroxyl radical is predominantly oxidant, because ferric ions can catalytically

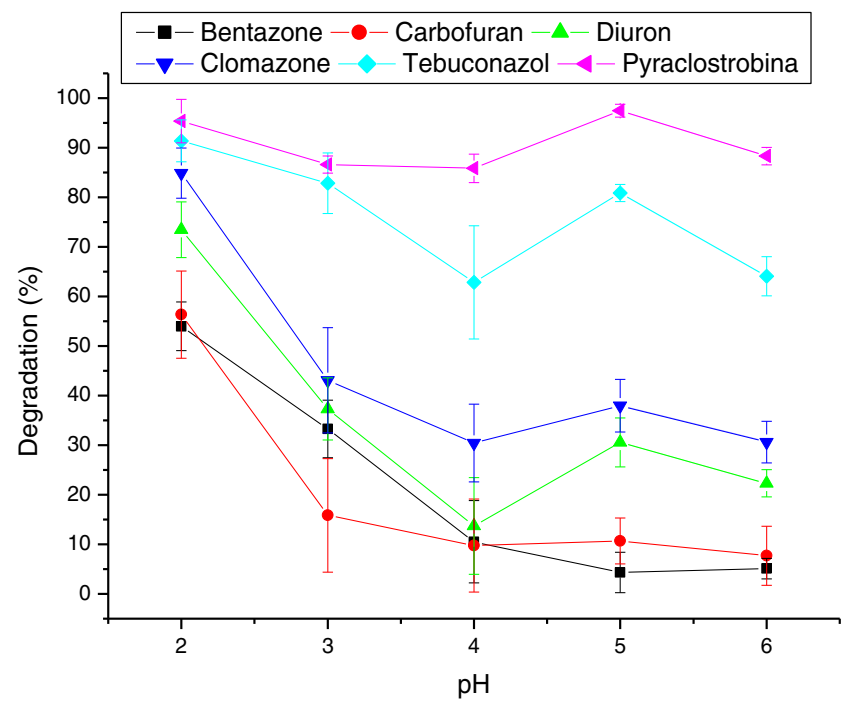

Fig. 4 Effect of different $\mathrm{pH}$ values on the pesticide degradation efficiency by Fenton's oxidation (experimental conditions: $5 \mathrm{mmol} \mathrm{L}^{-1}$ $\mathrm{H}_{2} \mathrm{O}_{2} ; 2.0$-g iron metal). Bars indicate the RSD percentage values 


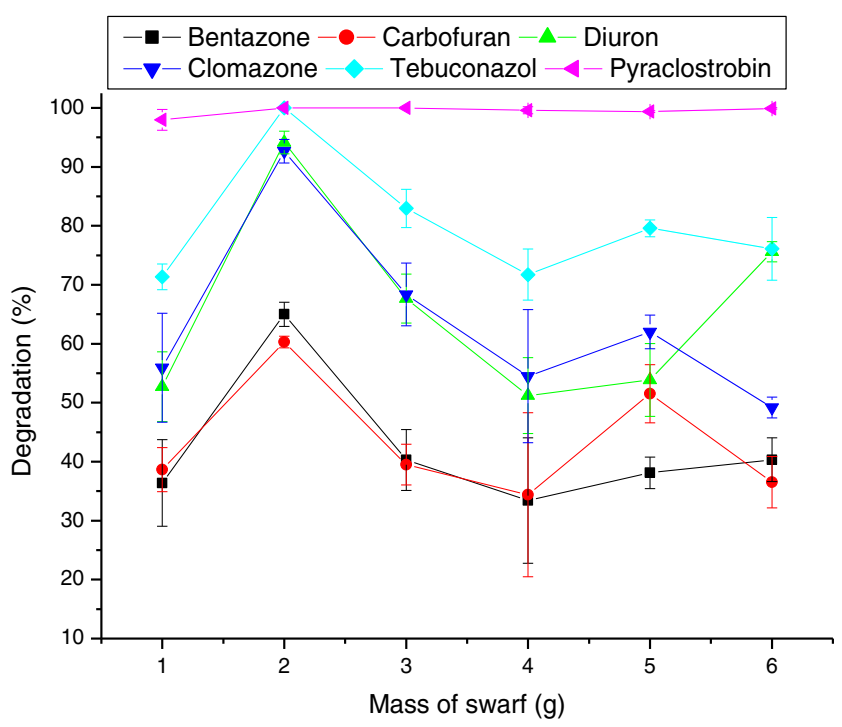

Fig. 5 Effect of different iron metal mass on the pesticide degradation efficiency by Fenton's oxidation (experimental conditions: $5 \mathrm{mmol} \mathrm{L}^{-1}$ $\mathrm{H}_{2} \mathrm{O}_{2} ; \mathrm{pH} 2.0$ ). Bars indicate the RSD percentage values

decompose hydrogen peroxide to $\mathrm{H}_{2} \mathrm{O}$ and $\mathrm{O}_{2}$ (Walling 1975; Laat and Gallard 1999).

The effect of acidic medium conditions on the degradation was studied with $\mathrm{pH}$ ranging from 2.0 to 6.0 . Figure 4 shows the values of degradation rates at different $\mathrm{pH}$. The $\mathrm{pH}$ effect on the degradation rates was carried out by fixing the swarf mass and hydrogen peroxide concentration. Percolating time was $20 \mathrm{~min}$ at laboratory temperature $\left(25^{\circ} \mathrm{C}\right)$. The highest degradation rates for all pesticides were obtained at $\mathrm{pH}$ 2.0. When $\mathrm{pH} \geq 3.0$, the Fenton's reactions showed lower degradation efficiencies than the value obtained at $\mathrm{pH} 2.0$ for all pesticides, except for pyraclostrobin and tebuconazole. On the other hand, when $\mathrm{pH}=2$, the hydroxyl radical can add to the aromatic ring and may also abstract a hydrogen atom and lead up to a radical chain oxidation (Walling 1975; Casero et al. 1996; Neyens and Baeyens 2003). Lu et al. have shown that the oxidation of carbofuran occurs when the radical hydroxyl attacks the furan ring ( $\mathrm{Lu}$ et al. 2011). These facts show that the $\mathrm{pH}$ of the medium also plays an important role in the degradation of these pesticides in this study. In addition, previous researches reported that $\mathrm{pH}=2$ are usually the best for the Fenton's reaction employing zero-valent iron (Kallel et al. 2009; Khan et al. 2009). Thus, $\mathrm{pH}=2.0$ was selected for further experiments.

\section{Effect of the amount of swarf}

For the determination of the optimum amount of swarf mass for the degradation rates of six pesticides, experiments were carried out with $\mathrm{pH} 2.0$ and $5 \mathrm{mmol} \mathrm{L}^{-1}$ hydrogen peroxide. The effect of the swarf mass was studied from 1.0 to $6.0 \mathrm{~g}$. The results of these experiments are shown in Fig. 5. The swarf mass improved the degradation efficiency up to $2.0 \mathrm{~g}$. On the other hand, its excess may inhibit the process efficiency due to the production of aqueous complexes, such as $\mathrm{Fe}$ (III)-hydroperoxy. Thus, 2.0-g swarf was chosen because this amount could promote better degradation rates of all pesticides, except for pyraclostrobin, since it presented high-degradation rates in all experiments.

\section{Degradation efficiency and mineralization employing} optimized conditions

When the best degradation conditions $\left(5 \mathrm{mmol} \mathrm{L}^{-1} \mathrm{H}_{2} \mathrm{O}_{2}\right.$, $\mathrm{pH} 2.0$, and 2.0-g swarf) were applied to the synthetic wastewater containing $10 \mathrm{mg} \mathrm{L}^{-1}$ of each pesticide, the highest degradation efficiency of these organic compounds was observed. Figure 6 shows the chromatographic profile for the synthetic wastewater before and after treatment by zerovalent iron and hydrogen peroxide.

Afterwards, an experiment was carried out to evaluate the degradation efficiency of the system at different reaction

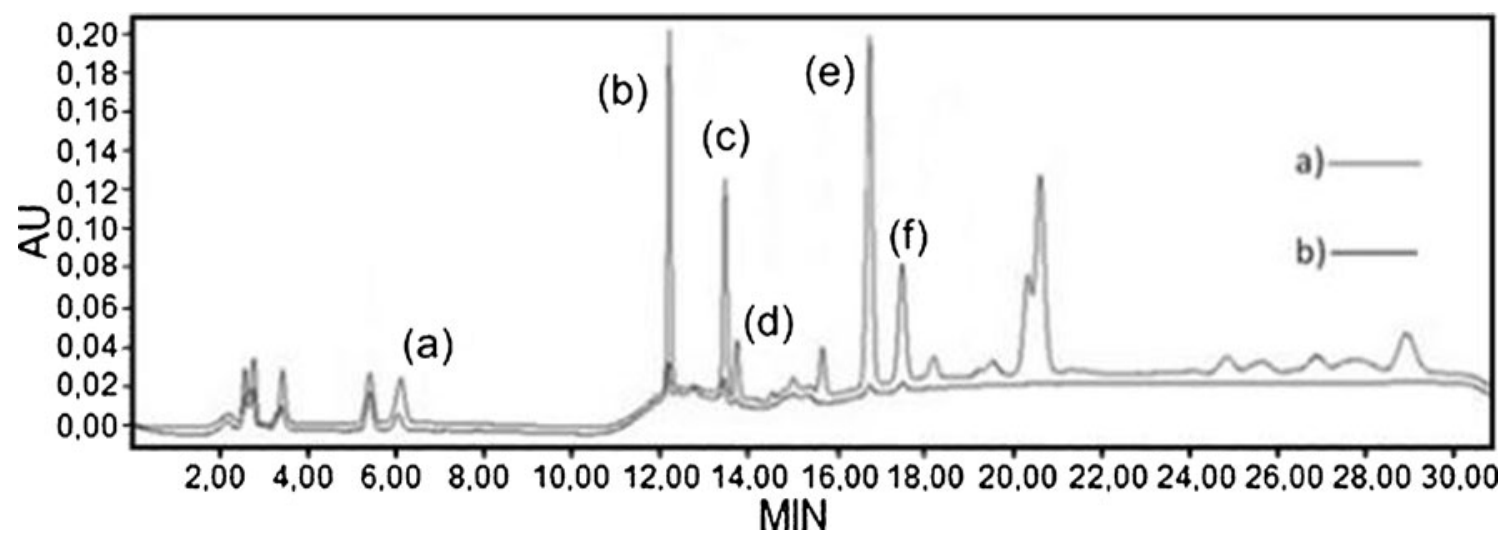

Fig. 6 Chromatograms of synthetic wastewater before (a) and after (b) treatment by valent-zero iron and hydrogen peroxide (experimental conditions: 5 mmol L ${ }^{-1} \mathrm{H}_{2} \mathrm{O}_{2} ; \mathrm{pH}$ 2.0; and 2.0-g iron metal). Where: bentazone $t_{r}$ of $5.9 \min (\mathbf{a})$, carbofuran $t_{r}$ of $12.1 \min (\mathbf{b})$, diuron $t_{r}$ of 13.4 min $(\mathbf{c})$, clomazone $t_{r}$ of $13.7 \mathrm{~min}(\mathbf{d})$, tebuconazole $t_{\mathrm{r}}$ of $17.1 \mathrm{~min}$ (e), and pyraclostrobin $\mathrm{t}_{\mathrm{r}}$ of $17.8 \mathrm{~min}$ (f) 


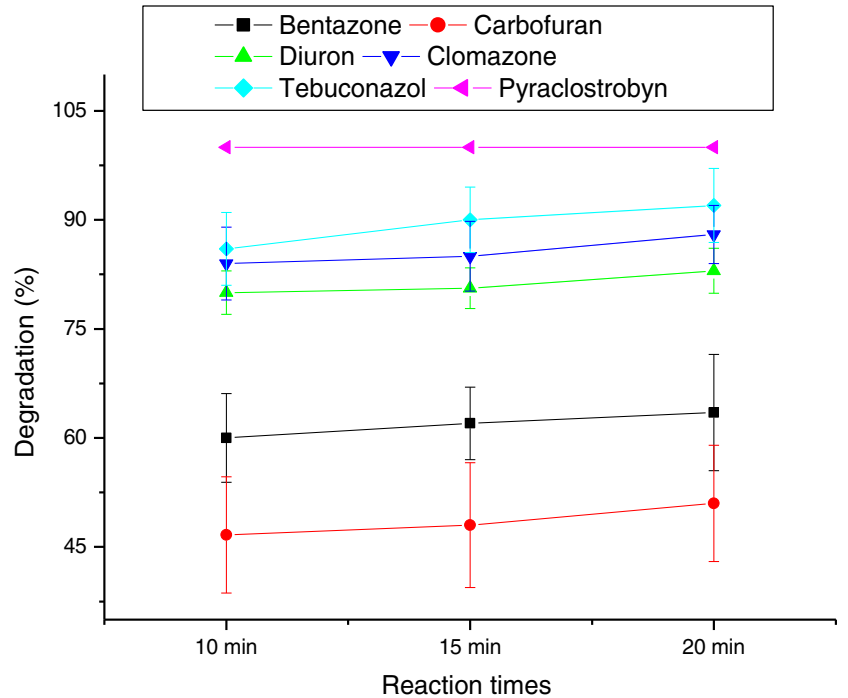

Fig 7 Degradation efficiency of the system at different reaction times (experimental conditions: 5 mmol L ${ }^{-1} \mathrm{H}_{2} \mathrm{O}_{2} ; \mathrm{pH} 2.0$; and 2.0-g iron metal). Bars indicated the RSD percentage values

times. Figure 7 shows that, after a 10 -min reaction time, the system showed degradation rates between 47 and $100 \%$. The higher the reaction time, the more the degradation rate increased, e.g., after $20 \mathrm{~min}$, the degradation rates were between 60 and $100 \%$.

In addition, a $t$ test was carried out to compare the results obtained for these experiments. ANOVA was applied to evaluate the statistical similarity among three degradation rates under study. The Tukey's multiple comparison test was used to indicate significant differences among the main degradation rates, with $95 \%$ significance level adopted for all comparisons. Results showed that the degradation rates at different reaction times were not significantly different $(t$ test, $P>0.05$ ).

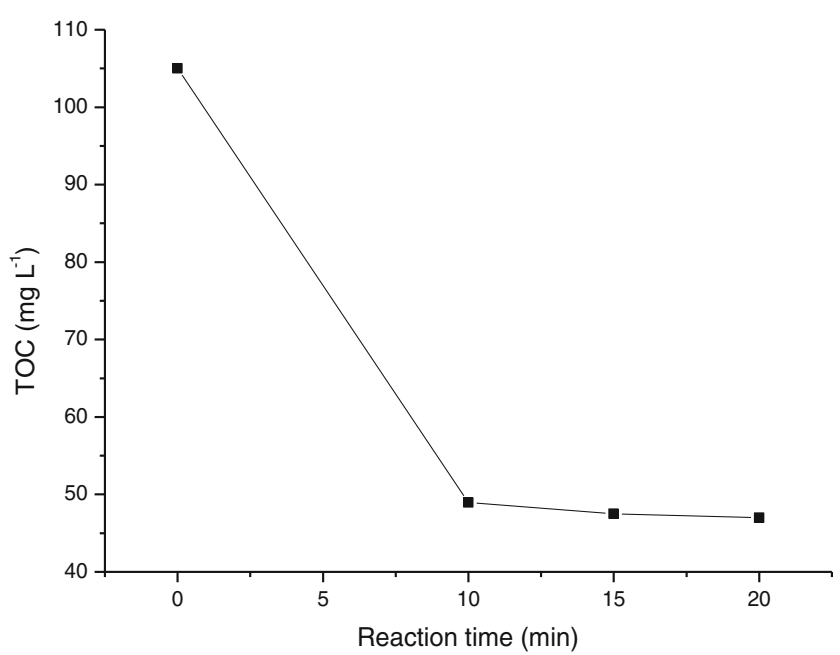

Fig. 8 Total organic carbon concentration during treatment (experimental conditions: $5 \mathrm{mmol} \mathrm{L}^{-1} \mathrm{H}_{2} \mathrm{O}_{2}$; $\mathrm{pH} 2.0$; and 2.0-g swarf)

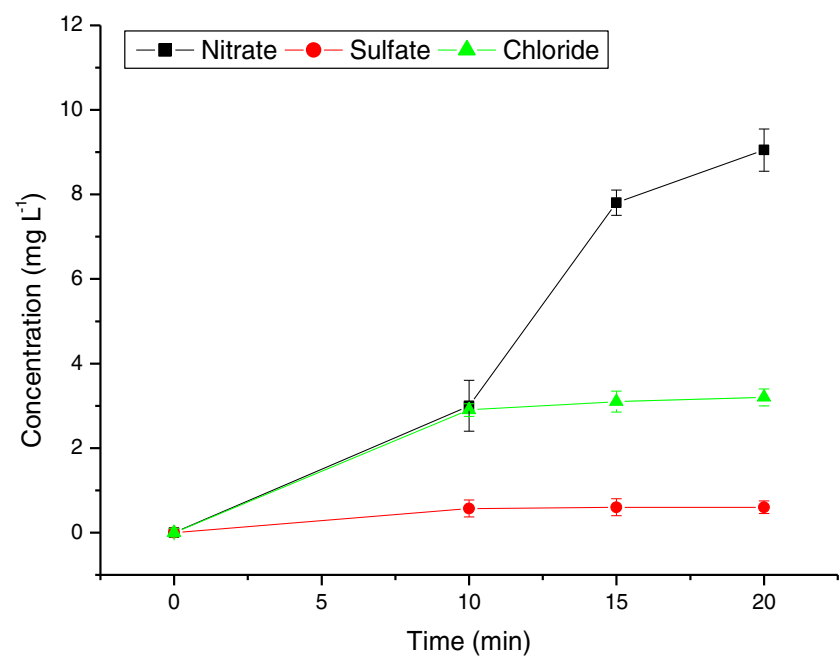

Fig. 9 Evaluated formation of $\mathrm{NO}_{3}{ }^{-}, \mathrm{Cl}^{-}$, and $\mathrm{SO}_{4}{ }^{2-}$ by ionic analysis (experimental conditions: $5 \mathrm{mmol} \mathrm{L}^{-1} \mathrm{H}_{2} \mathrm{O}_{2} ; \mathrm{pH}$ 2.0). Bars indicate the RSD \% values

Figure 8 shows that the system under development also resulted in an excellent degree of aqueous solution mineralization, with $55 \%$ mineralization after $20 \mathrm{~min}$. The NPOC value was reduced from 105 to $47 \mathrm{mg} \mathrm{L}^{-1}$. Furthermore, the ionic analysis by IC was used to confirm the mineralization of the aqueous solution. Results of this analysis (Figs. 9 and 10) revealed the formation of $\mathrm{NO}_{3}{ }^{-}, \mathrm{Cl}^{-}, \mathrm{PO}_{4}{ }^{2-}$, and $\mathrm{SO}_{4}{ }^{2-}$, which were detected in the following concentrations: 9.05 ; 3.2; 1,809.7; and $0.6 \mathrm{mg} \mathrm{L}^{-1}$, respectively; it complies with Brazilian laws regarding effluent disposal (National Environmental 2005).

The LC-ESI-MS/MS was used to evaluate the formation of carbofuran-3-hidroxy and 3,4 DCA by-products of pesticides carbofuran and diuron. This analysis revealed that these compounds were also removed during treatment of

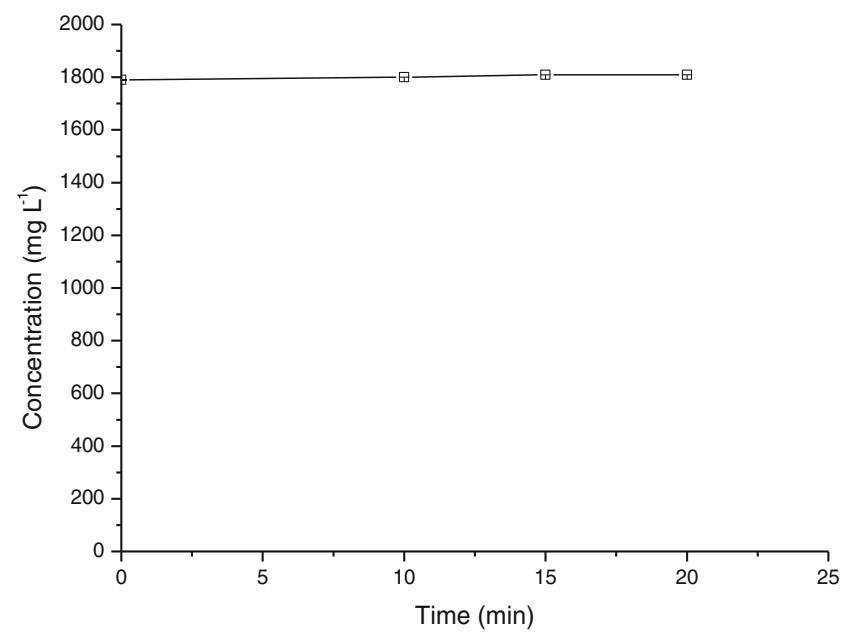

Fig. 10 Evaluated formation of $\mathrm{PO}_{4}{ }^{2-}$ by ionic analysis (experimental conditions: 5 mmol L ${ }^{-1} \mathrm{H}_{2} \mathrm{O}_{2} ; \mathrm{pH} 2.0$ ). Bars indicate the RSD percentage values 
synthetic wastewater. These by-products were detected in lower concentrations $\left(18 \mu \mathrm{g} \mathrm{L}^{-1}\right.$ of 3,4 DCA and $39 \mu \mathrm{g} \mathrm{L}{ }^{-1}$ of carbofuran-3-hidroxy) at the end of the treatment.

Considerations on tebuconazole and pyraclostrobin

As shown in Fig. 4, tebuconazole has the highest degradation rates for all $\mathrm{pH}$ values, a fact that can be explained by the hydrolysis and oxidation of tebuconazole in aqueous medium, due to the activity catalytic of the metals in the solution (Mann 2003; Calza et al. 2002). In addition, the highdegradation rates of the pesticide tebuconazole may be also explained by the extensive cleavage of the aromatic ring, producing degradates that lead to the mineralization (Calza et al. 2002).

The pesticide pyraclostrobin has low persistence in the environment. Hydrolysis was not observed in any value of $\mathrm{pH}$. In environmental conditions, hydrolysis will not be expected (APVMA, 2003). However, pyraclostrobin showed high-degradation efficiency for all hydrogen peroxide concentrations, $\mathrm{pH}$, and metal iron mass. It may occur due to the extensive cleavage and hydroxylation-type degradates that are formed together with the mineralization of the chlorophenyl side ring (APVMA, 2003).

\section{Determination of total dissolved iron}

At the end of the treatment, the determination of total dissolved iron using colorimetric determination by spectrophotometry (Associação Brasileira de Normas Técnicas ABNT 2010) resulted in $2 \mathrm{mg} \mathrm{L}^{-1} \mathrm{Fe}^{2+}$, which is in accordance with the Brazilian laws regarding effluent disposal (CONAMA, 2005).

\section{Determination of hydrogen peroxide residual}

The determination of hydrogen peroxide residual content employing the colorimetric method by spectrophotometry (Eisenberg 1975) revealed that all hydrogen peroxide was consumed at the end of the Fenton's process.

\section{Conclusions}

The system that was developed, based on Fenton oxidation with zero-valent iron and hydrogen peroxide for the degradation of six different classes of pesticides and chemical groups, proved to be efficient. The degradation efficiency was strongly affected by the $\mathrm{pH}$, the metal iron mass, and the hydrogen peroxide concentration. The best degradation conditions were $\mathrm{pH} 2.0,5 \mathrm{mmol} \mathrm{L}^{-1} \mathrm{H}_{2} \mathrm{O}_{2}$, and 2.0-g swarf. At the end of the treatment, total organic carbon was reduced
(55\% mineralization) and the degradation rates ranged from 60 to $100 \%$.

The advantages of this system are rapid degradation (up to $20 \mathrm{~min}$ ), high-degradation rates, simple handling, and low cost. In addition, it is an environmentally friendly and sustainable method because the source of the metal iron was swarf, a residue of a metallurgical activity. Besides, the aqueous complexes of ferric ions generated by this oxidation process during the treatment can start a new Fenton's reaction.

Acknowledgments The authors acknowledge the financial support and fellowships granted by the Brazilian agencies CAPES, FINEP, PETROBRAS, CORSAN and FURG. Part of this study was supported by a grant from the Brazilian Agency FAPERGS/CNPq (process number 010/0022-0), CNPq/CAPES (process number 552318/2011-6), CNPq (process number 477083/2011-00), FAPERGS (process number 11/0816-3), FAPERGS/PROCOREDES (process n0905342), CAPES/ PNPD (process number 23038.028239/2009-69). E.G. Primel received a produc; vity research fellowship from the Brazilian Agency CNPq (DT $310517 / 2012-5)$

\section{References}

ANC-135 (2012) Cations in drinking water using Metrosep C 4-150/ 4.0 column according to ISO 14911 and ANS-257 Seven standard anions separated on the column Metrosep A Supp 15-250/4.0 Metrohm Method, available at http://www.metrohm.com.br/ aplicacoes/Metodos2.html. Accessed 09 May 2013

Arruda TL, Jardim WF (2007) Treatment of groundwater contaminated with chlorinated compounds using elemental iron and Fenton's reagent. Quim Nova 30:1628-1632

Associação Brasileira de Normas Técnicas (ABNT) (2010) NBR 13934 Water - Iron Determination Phenantroline Colorimetric Method, available at http://www.abntcatalago.com.br. Accessed 23 Oct 2012

Australian Pesticides and Veterinary Medicines Authority (APVMA) (2003) Evaluation of the new active pyraclostrobin in the product cabrio fungicide. Public release summary Australian Pesticides and Veterinary Medicines Authority, 2003. Canberra - Australia ISBN 1448-3076

Barreiro JC, Capelato MD, Martin-Neto L, Hansen HCB (2007) Oxidative decomposition of atrazine by a Fenton-like reaction in a $\mathrm{H}_{2} \mathrm{O}_{2}$ /ferrihydrite system. Water Res 41:55-62

Benatti CT, Tavares CRG, Guedes TA (2006) Optimization of Fenton's oxidation of chemical laboratory wastewater using the response surface methodology. J Environ Manage 80:66-74

Benatti CT, Tavares CRG, Lenzi E (2009) Sulfate removal from waste chemicals by precipitation. J Environ Manage 90:504-511

Cabrera L, Costa FP, Primel EG (2008) Risk estimate of water contamination by pesticide in south of Brazil. Quím Nova 31:1982-1986

Cabrera L, Caldas SS, Rodrigues S, Bianchini A, Duarte FA, Primel EG (2010) Degradation of herbicide Diuron in water employing the $\mathrm{Fe}^{0} / \mathrm{H}_{2} \mathrm{O}_{2}$ system. J Braz Chem Soc 21:2347-2352

Caldas SS, Demoliner A, Costa FP, D’Oca MGM, Primel EG (2010) Pesticide residue determination in groundwater using solid-phase extraction and high-performance liquid chromatography with diode array detector and liquid chromatography-tandem mass spectrometry. J Braz Chem Soc 21:642-650

Calza P, Baudino S, Aigotti R, Baiocchi C, Branca P, Pelizzetti E (2002) High-performance liquid chromatographic/tandem mass spectrometric 
of the phototransformation products of tebuconazole on titanium dioxide. J Mass Spectrom 37:566-576

Casero I, Sicilia D, Rubio S, Pèrez-Bendito D (1996) Chemical degradation of aromatic amines by Fenton's reagent. Water Res 31:1985-1995

Demoliner A, Caldas SS, Costa FP, Gonçalves FF, Clementin RM, Milani MR, Primel EG (2010) Development and validation of a method using SPE and LC-ESI-MS-MS for the determination of multiple classes of pesticides and metabolites in water samples. J Braz Chem Soc 21:1424-1434

Eisenberg GM (1975) Colorimetric determination of hydrogen peroxide. Ind Eng Chem 15:327-328

Fan C, Tsui L, Liao MC (2011a) Parathion degradation and its intermediate formation by Fenton process in neutral environment. Chemosphere 82:229-236

Fan X, Hao H, Shen X, Chen F, Zhang J (2011b) Removal and degradation pathway study of sulfasalazine with Fenton-like reaction. J Hazard Mater 190:493-500

Fatta D, Canna-Michaelidou S, Michael C, Georgiou ED, Christodoulidou M, Achilleos A, Vasquez M (2007) Organochlorine and organophosphoric insecticides, herbicides and heavy metals residue in industrial wastewaters in Cyprus. J Hazard Mater 145:169-179

Fatta D, Michael C, Canna-Michaelidou S, Christodoulidou M, Kythreotou N, Vasquez M (2006) Pesticides, volatile and semivolatile compounds in the surface waters of Cyprus. Desalination 215:223-236

Gooddy DC, Chilton PJ, Harrison I (2002) A field study to assess the degradation and transport of diuron end metabolites in a calcareous. Sci Total Environ 7:67-83

Gözmen B, Kayan B, Gizir AM, Hesenov A (2009) Oxidative degradations of reactive blue 4 dye by different advanced oxidation methods. J Hazard Mater 168:129-136

Gulkaya I, Surucu GA, Dilek FB (2006) Importance $\mathrm{H}_{2} \mathrm{O}_{2} / \mathrm{Fe}^{2+}$ ratio in Fenton's treatment of a carpet dyeing wastewater. J Hazard Mater 136:763-769

Hermosilla D, Cortijo M, Huang CP (2009) The role of iron on the degradation and mineralization of organic compounds using conventional Fenton and photo-Fenton processes. Chem Eng J 155:637-646

Jiang C, Pang S, Ouyang F, Ma J, Jiang J (2010) A new insight into Fenton and Fenton-like process for water treatment. J Hazard Mater 174:813-817

Kallel M, Belaid C, Boussahel R, Ksibi M (2010) Olive mill wastewater degradation by Fenton oxidation with zero-valent iron and hydrogen peroxide. J Hazard Mater 163:550-554

Kallel M, Belaid C, Mechichi T, Ksibi M, Elleuch B (2009) Removal of organic load and phenolic compounds from olive mill wastewater by Fenton oxidation with zero-valent iron. Chem Eng J 150:391395

Kassinos D, Constantinou M, Varnava N, Papadopoulos A, Vlachos S, Mantzavinos D (2008) Oxidation of pesticides in water by Fenton and photo-Fenton reactions. J Adv Oxid Technol 11:246-253

Kassinos D, Varnava N, Michael M (2009) Homogeneous oxidation of aqueous solutions of atrazine and fenitrothion through dark and photo-Fenton reactions. Chemosphere 74:866-872

Khan E, Wirojanagud W, Sermsai N (2009) Effects of iron type in Fenton reaction on mineralization and biodegrability enhancement of hazardous organic compounds. J Hazard Mater 161:1024-1034
Klavarioti M, Mantizavinos D, Kassinos D (2011) Removal of residual pharmaceuticals from aqueous system by advanced oxidation processes. Environ Int 35:402-417

Laat J, Gallard H (1999) Catalytic decomposition of hydrogen peroxide by $\mathrm{Fe}(\mathrm{III})$ in homogeneous aqueous solution: mechanism and kinetic modeling. Environ Sci Technol 33:2726-2732

Lu LA, Ma YS, Kumar M, Lin JG (2011) Photochemical degradation of carbofuran and elucidation of removal mechanism. Chem Eng J $166: 150-156$

Mann PJ (2003) The e-pesticide manual, 13th ed. Version 3.0. British Crop Protection Council (BCPC), Alton, UK

Martín MMB, López JLC, Oller I, Malato S, Sánches-Pérez JA (2010) A comparative study of different tests for biodegrability enhancement determination during AOP treatment of recalcitrant toxic aqueous solutions. Ecotoxicol Environ Saf 73:1189-1195

Masomboon N, Chen CW, Anotai J, Lu MC (2010) A statistical experimental design to determine O-toluidine degradation by the photoFenton process. Chem Eng J 159:116-122

Melo SAS, Trovó AG, Bautitz IR, Nogueira RFP (2009) Degradation of residual pharmaceuticals by advanced oxidation process. Quim Nova 32:188-197

Namkung KC, Burgess AE, Bremmer DH, Staines H (2008) Advanced Fenton processing of aqueous phenol solutions: a continuous system study including sonication effects. Ultrason Sonochem $15: 171-176$

National Environmental Council (2005) (Ministério do Meio Ambiente, Conselho Nacional do Meio Ambiente) (CONAMA). Resolution no 357,03/17/2005. Available at http://www.mma.gov.br/port/ conama/rs/res05/res35705.pdf Accessed 05 Dec 2012

Neyens E, Baeyens J (2003) A review of classic Fenton's peroxidation as an advanced oxidation technique. J Hazard Mater 98:33-50

Oller I, Malato S, Sánches-Pérez JA (2011) Combination of advanced process and biological treatments for wastewater decontamination - a review. Sci Total Environ 409:4141-4166

Oturan MA, Oturan N, Edelahi MC, Podvorica FI, Kacemi K (2011) Oxidative degradation of herbicide diuron in aqueous medium by Fenton's reaction based advanced oxidation processes. Chem Eng J 171:127-135

Oturan N, Trajkovska S, Oturan MA, Couderchet M, Aaron JJ (2008) Study of the toxicity of diuron and its metabolites formed in aqueous medium during application of the electrochemical advanced oxidation process "electro-Fenton". Chemosphere 73:1550-1556

Pérez MH, Peñuela G, Maldonado MI, Malato O, Fernández-Ibañez P, Oller I, Gernjak W, Malato S (2006) Degradation of pesticides in water using solar advanced oxidation process. Appl Catal B Environ 64:272-281

Satapanajaru T, Comfort SD, Shea PJ (2003) Pilot-scale treatment of RDX-contaminates soil with zero-valent iron. J Environ Qual 32:1717-1725

Scherer MM, Johnson KM, Westall JC, Tratnyek PG (2001) Mass transport effects on the kinetics of nitrobenzene reduction by iron metal. Environ Sci Tecnol 35:2804-2811

Tang WZ, Tassos S (1997) Oxidation kinetics and mechanism of trihalomethanes by Fenton's reagent. Water Res 31:1117-1125

Walling C (1975) Fenton's reagent revisited. Acc Chem Res 8:125-131

Zapata A, Velegraki T, Sánchez-Pérez JA, Mantzavinos D, Maldonado MI, Malato S (2009) Solar photo-Fenton treatment of pesticides in water: effect of iron concentration on degradation and assessment of ecotoxicity and biodegrability. Appl Catal B Environ 88:448-454 